\title{
La participación de los ciudadanos en la vida local. $S u$ configuración en el nuevo ordenamientos municipal venezolano
}

\author{
José Luis Villegas Moreno ${ }^{1}$
}

Sumario: I. INTRODUCCIÓN. II. PARTICIPACIÓN Y DEMOCRACIA: MOTIVOS DE PARTICIPACIÓN, TENDENCIAS GENERALES, OBSERVATORIO INTERNACIONAL DE DEMOCRACIA PARTICIPATIVA. III. PROXIMIDAD Y SUBSIDIARIEDAD. IV. CONFIGURACIÓN DE LA PARTICIPACIÓN EN LA VIDA LOCAL EN VENEZUELA: DESARROLLO CONSTITUCIONAL Y LEGAL.

\begin{abstract}
«La participación protagónica del pueblo en la formación, ejecución y control de la gestión pública municipal es el medio necesario para garantizar su completo desarrollo tanto individual como colectivo, dentro del Municipio. Las autoridades municipales deberán promover y garantizar la participación de los ciudadanos y ciudadanas en la gestión pública y facilitar las formas, medios y procedimientos para que los derechos de participación se materialicen de manera efectiva, suficiente y oportuna».(Art.1, Ley Orgánica del Poder Público Municipal ).
\end{abstract}

\section{INTRODUCCIÓN}

Siguiendo a Antonio Iglesias ${ }^{2}$ creemos que la concurrencia en el individuo de la distinción de su carácter de ciudadano del planeta en un mundo globalizado, por un lado, y de su barrio (o pueblo) como centro de una cultura propia, que crea unos comportamientos y unas interacciones sociales intensas propias de la búsqueda de las identidades, por otro, plantea la necesidad de profundizar en la democracia local para hacerla representativa y participativa, evitando la apatía.

La participación es el término clave del sistema democrático. Así, junto al control institucional que otros órganos, también representativos, deben ejercer, está también el control directo del pueblo soberano a través de las

\footnotetext{
${ }^{1}$ Doctor en Derecho. Profesor de Derecho Administrativo de la Universidad Católica del Táchira, Venezuela. Miembro de la Asociación Iberoamericana de Profesores e Investigadores de Derecho Administrativo.

2 Antonio Iglesias MarTín, Autonomía municipal, descentralización política e integración europea de las entidades locales, Ariel Derecho, Barcelona 2002.
} 
distintas formas de participación. Así las cosas, consideramos que el ciudadano ha de ser mas consciente que nunca que el sentimiento democrático alcanza hoy su más alta expresión en la idea de participación.

Este parece ser el contexto de la Constitución venezolana de 1999 y de la Ley Orgánica del Poder Público Municipal. Aunque los postulados de participación constituyen un desafío ambicioso que sólo se realizará si se produce un esfuerzo sostenido de todos los actores sociales en el cambio profundo de paradigma político ${ }^{3}$. La participación no se decreta, es necesario insertarla en un contexto de valores esenciales para constituir una sociedad verdaderamente participativa.

Uno de los objetivos de la participación es mejorar la gestión pública local, para que se acerque a la excelencia, a la calidad total. El motor que impulsa a la Administración Pública Local a trabajar con calidad es el afán de sostener o incrementar su legitimidad.

El tema central a resolver cuando se trata de la participación democrática, es determinar cómo y en qué lugar la misma puede realizarse. Sólo en los niveles territoriales inferiores de la organización del Estado en que se puede montar una organización participativa que permita la incorporación del ciudadano individual, o en grupos o en comunidades, en la vida pública, $\mathrm{y}$ particularmente, en la toma de decisiones públicas generales o de orden administrativo ${ }^{4}$.

El tema de la participación ciudadana en la vida administrativa es un concepto contemporáneo. Hasta el siglo XIX la Administración era considerada como un poder autosuficiente, separado de los particulares, aislado del control social, ya que los particulares no participaban en las decisiones de la Administración.

La idea de participación ciudadana surge como respuesta crítica al Estado liberal, al modelo burocrático de administrar, en el que los funcionarios públicos estaban aislados del medio social, y por ello sus decisiones no tenían sustrato real. La adecuación de la Administración al entorno social obligó a crear mecanismos de participación que perforaran esa impermeabilidad de la Administración. Así, la participación ciudadana se va a des-

\footnotetext{
3 Manuel Feo la CRUZ, La participación de la sociedad civil en el proceso de gestión pública. Retos y desafios, en la obra colectiva El Derecho Público a comienzos del siglo XXI: Estudios en homenaje al profesor Allan R. Brewer-Carías, Civitas, Madrid 2003.

4 Véase Allan R. BREWER-CARÍAS, Sobre la globalización, la lugarización y el pequeño municipio, Provincia, $n^{\circ}$ 12, julio-diciembre, 2004, Cieprol-Ula, Mérida 2005.
} 
arrollar en el contexto de una serie de cambios que se fueron operando con el advenimiento del Estado Social, entre los que podemos destacar:

1. La descentralización territorial a los niveles regionales y locales.

2. El cambio en la concepción del poder de la Administración, de mero garante del orden público a prestador activo de servicios. En este sentido se aspira a una conciliación entre los intereses de la Administración (generales) con la voluntad de los particulares.

3. La economía concertada implica que la Administración solicita la colaboración de los particulares para administrar conjuntamente los bienes y servicios, a través de diferentes convenios.

El IV Foro de Autoridades Locales por la Inclusión Social se ha celebrado en Barcelona previo al inicio del Forum Universal de las Culturas. Este Foro de Autoridades Locales reconoce que la inclusión social pasa por el fomento y compromiso con la participación ciudadana y la democracia participativa, reconociendo la capacidad que las personas tienen para incidir en su realidad social concreta. Las ciudades no podrán mejorar si la ciudadanía no tiene mecanismos directos de intervención en las decisiones que afectan a sus vidas. En este importante Foro se creó una nueva organización que lleva por nombre «Ciudades y Gobiernos Locales Unidos» ${ }^{5}$.

En este mismo sentido está enfocada la Declaración de La Antigua que lleva por título: ¿Exclusión social? Una agenda para los objetivos del Milenio $^{6}$. En este importante documento se concluye que frente a los fenómenos de exclusión social de los municipios iberoamericanos, espacios públicos por excelencia desde los orígenes de la democracia, están llamados a rehacer el protagonismo de lo público y a trabajar por la igualdad de las personas.

\section{PARTICIPACIÓN Y DEMOCRACIA}

El debate sobre la participación de los ciudadanos en la vida pública de sus comunidades reposa esencialmente en un postulado, a saber, que dicha participación es una característica deseable de la democracia. En particular, se considera generalmente que un bajo nivel de participación en el proceso democrático es un síntoma preocupante y un factor que afecta al funcionamiento de la democracia local.

5 Declaración de Barcelona, 08 de mayo de 2004. Web Forum Barcelona 2004.

6 VII Congreso Iberoamericano de Municipalistas, Guatemala, Octubre 2004. 
En este contexto, cabe preguntarse:¿En qué medida la participación es deseable? ¿De qué manera debe fomentarse? La teoría moderna de la democracia aporta varias respuestas a estas dos preguntas desde al menos cuatro perspectivas ${ }^{7}$.

\section{Perspectiva realista}

Según una opinión generalizada, la política existe para expresar y defender intereses. La participación servirá entonces para promover estos objetivos con resultados óptimos y un coste mínimo. Es necesario, en este caso, que los participantes confíen en sí mismos y tengan cierta eficacia. También se podría esperar de ellos cálculos «racionales» que permitan apreciar el valor de su contribución.

Parece que esta perspectiva instrumental de la participación favorece una comprensión realista de las cuestiones en juego. Los ciudadanos participan en la vida pública si se plantea un problema que les interesa y si creen en la eficacia de su intervención. La participación tendería a ser una actividad donde sólo intervendrá de manera puntual. Un reducido nivel de interés y una apreciación realista de las obligaciones del poder disuaden a muchos ciudadanos de tener un papel más activo. Lo importante sería entonces crear mecanismos y disponer de las capacidades deseadas para convencer a un número suficiente de ciudadanos sobre la utilidad de su movilización, en cuanto se plantearan problemas importantes.

\section{Perspectiva participativa}

Una perspectiva totalmente opuesta a la de los realistas es la que adoptan aquellos que ven en la democracia un proceso que necesita la mayor participación posible del ciudadano. Subyacen dos maneras de pensar en esta perspectiva. La primera perspectiva -comunitaria- alega que la contribución a la vida política no depende de un cálculo utilitario sino más bien de un interés de bienestar de la colectividad, de la que son parte. La segunda acentúa el valor de la participación en tanto que experiencia educativa. Cooperando y en confianza. Además, también pueden comprender mejor los intereses y las aspiraciones de sus conciudadanos.

7 Ver el documento INAP-25, La participación en la vida pública local, Madrid 1999. 
Esta perspectiva participativa confiere una virtud particular a la vida pública local. Este nivel político es fácilmente accesible y su proximidad hace de él una base ideal de participación. Ofrece un foro donde los intereses colectivos pueden ser explorados y en el que los ciudadanos son introducidos en el mundo de la política de una manera que les permite aprender y evolucionar.

Estos argumentos, a veces algo paternalistas, se interesan esencialmente en la participación en tanto que medio para la autoexpansión y la expresión de las preocupaciones colectivas.

\section{Política de presencia}

La política de presencia se basa en la demanda de los grupos excluidos para que sean implicados en la toma de decisiones. No piden sólo que sus opiniones se tomen en cuenta, sino que también sean representados en la vida política por los individuos que comparten su experiencia y su identidad.

Se esgrime que la presencia de estos grupos pone en duda, de múltiples maneras, las estructuras existentes de exclusión y de marginalización. En primer lugar, el hecho de que los miembros del grupo excluido estén presentes en la mesa en la que se estudian las decisiones tiene un valor simbólico. La representatividad no sólo debe existir, sino que también tiene que poder verse. En esta perspectiva, la participación tiene un aspecto expresivo: los ciudadanos actúan para expresar sus sentimientos y su identidad.

Sin embargo, la política de presencia -tal y como la perciben, por ejemplo, los movimientos feministas o algunas organizaciones de personas inválidas- reposa sobre la hipótesis de que esta presencia directa de representantes del grupo influye en la toma de decisiones. Abriría el proceso de decisiones y crearía las condiciones para una defensa más enérgica de los intereses a los que se aspira. Además, facilitaría las transformaciones dando a las categorías anteriormente excluidas el tiempo y la oportunidad para construir sus preferencias políticas y expresar sus preocupaciones.

\section{Democracia deliberativa}

Uno de los elementos del debate sobre la participación, que es más relevante hoy que hace unos treinta años, es la política de deliberación. Los 
que sostienen esta idea critican los argumentos favorables al acercamiento utilitario y a la política de presencia porque les parecen demasiado orientados al interés personal. A diferencia de los partidos de la democracia directa o participativa, los de la democracia deliberativa no ven necesariamente en una participación máxima un bien en sí.

Aunque, sin embargo, apoyan una amplia participación, desaprueban las estructuras que reflejan una concepción utilitaria de la política, reducida a un conflicto de intereses en el cual el Gobierno tiene por cometido encontrar un equilibrio entre las demandas opuestas. Las instituciones políticas deben más bien ser concebidas para permitir a los ciudadanos que creen relaciones entre ellos en el marco de las deliberaciones o de las argumentaciones y no sólo en calidad de negociadores en busca de intercambios.

Los defensores de esta idea sugieren, sobre todo, que la política debe implicar un razonamiento, un debate abierto y una reflexión sobre las opiniones de los demás. Si la mayor parte no cree obligatoriamente de manera simplista en el descubrimiento de soluciones de «interés general», todos opinan que durante la deliberación aparecen posiciones y elementos de entendimiento nuevos. La participación estructurada de manera deliberativa llevaría de este modo a soluciones inéditas y a una toma de decisiones más satisfactoria.

\section{Los motivos de participación ${ }^{8}$}

Evidentemente, los motivos de participación son variables. El ciudadano antepone el aspecto utilitario, expresivo o deliberativo, o la toma como un deber cívico. Confiere la legitimidad requerida a los órganos públicos, así como los conocimientos necesarios para una toma de decisiones eficaz. Por último, permite asegurar el apoyo activo a los ciudadanos para llegar a un objeto concreto.

En términos instrumentales, la participación puede ser considerada como un medio para que los individuos alcancen sus objetivos. Contribuyen a una acción si una cuestión les interesa lo suficiente y si piensan que vale la pena hacer este esfuerzo. En la mayor parte de los casos, sin embargo, los ciudadanos permanecen inactivos. Algunos estiman que esta apatía es el resultado de un nivel de interés muy bajo. Para otros, refleja un poder político inadecuado.

\footnotetext{
8 Seguimos las conclusiones del Observatorio Internacional para la Democracia Participativa, Documentos INAP-25, 1999.
} 
Algunos aprecian la participación en sí misma, estimando que expresa el interés de la colectividad de la que son parte y ofrece la posibilidad de iniciarse en el arte de la ciudadanía. Puede parecer difícil en el mundo moderno limitarse a esta idea clásica, incluso romántica, de la participación.

Para los defensores de una política de presencia, la participación de representantes de los grupos excluidos tiene una importancia simbólica y utilitaria. Demuestra la inclusión del grupo y de sus intereses y ofrece un mejor entorno para trabajar a favor de estos últimos. No es necesario que todos los miembros del grupo se comprometan en la actividad política, pero sí la presencia, en el espacio en el que se toman las decisiones, de representantes con los que puedan identificarse y que hayan compartido su experiencia, lo cual facilitará la expresión de sus intereses colectivos.

Los que apoyan la participación estructurada con objeto de ampliar el debate se sitúan en otra perspectiva. Sostienen que la participación no tiene valor en sí y su objetivo primordial es la creación de una estructura de deliberación que permita a los ciudadanos intercambiar opiniones, revisar su comprensión sobre cuestiones importantes y encontrar soluciones comunes. Es conveniente entonces alentar la participación de un abanico limitado de personas, de manera que se fomente el debate y la búsqueda del interés general.

El debate sobre las posibles opciones en materia de reforma depende de la razón de ser de la participación o del valor que se le atribuya. Encontramos, sin duda, en todos los Estados una mezcla de estas motivaciones con quizá una predominancia del punto de vista realista o utilitario. Además de esto, el reto consiste en crear sistemas de democracia local en los que los ciudadanos tengan la posibilidad de participar, pero que, en caso de que éstos eligieran no explotar estas posibilidades, permanezcan legítimas y eficaces. Los puntos cruciales son el carácter abierto de las instituciones y la conciencia de los ciudadanos que pueden influir en una decisión si sienten la necesidad.

Por otra parte, muchos Estados desean encontrar en su régimen de democracia local una mayor capacidad de participación, reflejada por la presencia de varios grupos sociales y económicos y/o la capacidad de comprometerse en una política más deliberativa y más orientada hacia la reflexión, que reúna los múltiples intereses en busca de una visón común de colaboradores con vistas a una acción colectiva. 


\section{Tendencias generales que marcan la participación 9}

La experiencia de la participación de los ciudadanos en sus diversas formas varía de un país a otro. Existe, sin embargo, un cierto número de tendencias generales, que se manifiestan con diversos grados en todos los Estados miembros del Consejo de Europa. Estas tendencias demuestran que es importante que todos los países vigilen la calidad de la participación de los ciudadanos en la vida local preparando programas destinados a responder las necesidades a medida que éstas toman un carácter de urgencia. Las tendencias generales que marcan la participación en todos los países son las siguientes:

\section{El impacto de las nuevas técnicas de información y de comunicación}

Estas técnicas proporcionan a los ciudadanos los medios para intercambiar rápidamente información y conocimientos. También ofrecen nuevas oportunidades para pronunciarse mediante el voto o, de un modo más amplio, intervenir en las decisiones gubernamentales. La tecnología no determina la política, pero sí presenta nuevas expectativas y posibilidades.

\section{El impacto de la globalización en la estructura política local}

Si existe desde hace algún tiempo toda una red de interconexiones mundiales, también es cierto que se ha producido una intensificación tanto de la internacionalización de los asuntos interiores de los Estados como de la envergadura de la toma de decisiones en el ámbito internacional. Las cuestiones económicas y medioambientales son, por ejemplo, dos campos en los que las dimensiones nacionales e internacionales están más ligadas que anteriormente. La internacionalización de la toma de decisiones, que aparece en la legislación, las reglas y los convenios a escala local, se manifiestan en numerosos sectores.

El proceso de globalización tiene incidencias en la política de los Estados a la vez que reduce el espacio dejado a la política local y, en definiti-

\footnotetext{
${ }^{9}$ Informe del Comité Director para la democracia local y regional del Consejo de Europa, Municipios y Regiones de Europa, en La participación de los ciudadanos en la vida pública local, Documentos INAP-25, Ministerio de Administraciones Públicas, Madrid 2002.
} 
va, pone en duda el valor de la participación de los ciudadanos en la vida local. Si las «verdaderas» decisiones e influencias están en otra parte, ¿para qué sirve la política local? O, para darle la vuelta al razonamiento, si el Gobierno legítimo se apoya en el acuerdo de aquellos a los que afecta una decisión, ¿cómo es posible que en un universo marcado por la globalización y las múltiples interconexiones, pueda dejarse que este acuerdo se exprese dentro de los límites tradicionales de las estructuras políticas? El horizonte geográfico de la vida política se ha ampliado. Puede ser que los ciudadanos sean capaces de «pensar a escala mundial y de actuar a escala local», pero la aparición de una sociedad global exige al menos una redefinición de la finalidad y del estilo de la vida política local.

\section{El impacto de las estructuras cambiantes del empleo y del crecimiento económico}

Las economías modernas exigen una mano de obra más instruida, una participación mayor de las mujeres en la vida profesional y, para muchos, un trabajo más intenso, mientras que algunos se ven obligados a integrarse más en la economía, otros están sufriendo la experiencia de la exclusión económica y social. Estas evoluciones afectan de diversas maneras a la propensión de tomar parte en la vida política. Aquellos que están más preparados son en general los ciudadanos que tienen un cierto grado de instrucción. Los obstáculos para el compromiso político ligados al sexo tienden a fundarse en los cambios más importantes que afectan a la sociedad.

Sin embargo, la intensidad de las exigencias profesionales limita el tiempo que muchos pueden consagrar a la política y el interés que puede aportarle, ya que los «logros» más importantes y los «éxitos» políticos que ponen de relieve la providencia del Estado pueden hacer que se pierda interés, en la medida en que pueden encontrar mejor camino en el sector privado. En cuanto a aquellos que sufren una exclusión económica y social, la desilusión, la apatía y un sentimiento de impotencia pueden mantenerles separados de la vida pública.

\section{Observatorio Internacional de Democracia Participativa}

En Europa se ha puesto en marcha el «Observatorio Internacional de Democracia Participativa», una red en la que han jugado un papel esencial como coordinadoras las ciudades de Porto Alegre, Barcelona y Sant 
Denis. La primera Conferencia Internacional de Democracia Participativa se celebró en Porto Alegre en noviembre de 1999 y en ella las cien ciudades participantes suscribieron un documento en el que resumían los principios y objetivos inspiradores de la participación democrática de los ciudadanos en la toma de decisiones que les afectan. En el transcurso de la II Conferencia Internacional de Democracia Participativa, celebrada en Saint Dennis en septiembre de 2000 bajo el lema «por un derecho a la ciudad: hacia una nueva ciudadanía», y muy conectada con la II Conferencia Europea sobre los Derechos Humanos en la Ciudad, se ha llegado aún más lejos desde el llamado «Presupuesto Participativo» de Porto Alegre, en virtud del cual los vecinos tienen la posibilidad, a través de medios técnicos, de intervenir en la determinación de los gastos municipales, u otras propuestas como la gestión de barrios, el plan estratégico de decisiones, etc. En Saint Dennis se puso de manifiesto que los municipios son los lugares donde se producen de forma más clara las tensiones, las desigualdades y las exclusiones, y que la democracia participativa se configura como algo que favorece la convivencia, la libertad y la igualdad de los ciudadanos. Por ello se crea como espacio internacional de intercambio y de reflexión el Observatorio Internacional de Democracia Participativa, que nace con el objetivo de promover el enfoque participativo, inscribiéndolo en una dinámica de intercambio con fuerza de valor universal y vocación de ampliarse a otros niveles de decisión.

En el Forum $2004^{10}$ en Barcelona se presentó la Carta de los Derechos Emergentes. El artículo 7 está dedicado a la democracia participativa y a los derechos conexos que ella implica. Así establece que todos los seres humanos y los pueblos en que se integran tienen derecho a participar activamente en los asuntos públicos y a disfrutar de una administración democrática en todos los niveles de gobierno.

Este derecho humano fundamental comprende los siguientes derechos:

1. El derecho a la ciudad, que asegura que todo ser humano y los pueblos en que se integran encuentren en la ciudad las condiciones para su plena realización política, económica, social, cultural y ecológica.

2. El derecho a la movilidad universal, que reconoce el derecho de toda persona a migrar y establecer su residencia en el lugar de su elección.

3. El derecho universal al sufragio activo y pasivo, que ampara el derecho de toda persona mayor de edad, con independencia de su nacionalidad, al sufragio activo y pasivo en todos los procesos

10 www.forum 2004barcelona.com, carta de los derechos humanos emergentes. 
electorales y consultas populares que se celebren en su lugar de residencia habitual.

4. El derecho a ser consultado, que garantiza el derecho de todos los seres humanos a ser consultados colectivamente en las decisiones que les afecten.

5. El derecho a la participación, que implica el derecho de toda persona y de los pueblos en que se integran a participar, mediante cauces ágiles y eficaces, en la adopción y control de decisiones públicas en las materias que les conciernan, así como a impugnar ante los tribunales aquellas decisiones respecto de las que aleguen un derecho o un interés directo o indirecto como fundamento de su legitimación.(cursivas nuestras).

6. El derecho a la vivienda y a la residencia, que garantiza a todo ser humano el derecho a mantener su residencia en el lugar donde tiene sus relaciones sociales, en sus entornos significantes, o a tener otro de su libre elección.

7. El derecho al espacio público y a la monumentalidad, que supone el derecho a un entorno articulado por un sistema de espacios públicos y dotados de elementos de monumentalidad que les den visibilidad e identidad.

8. El derecho a la belleza, de manera que el espacio urbano incorpore una dimensión estética y un urbanismo armonioso y sostenible como prueba de la calidad urbana.

9. El derecho a la identidad colectiva en la ciudad, que significa el derecho a una organización interna del espacio urbano que facilite la cohesión sociocultural de las comunidades.

10. El derecho a la movilidad y a la accesibilidad, pues toda persona tiene derecho a un tráfico ordenado y respetuoso con el medio ambiente y a moverse con facilidad por la ciudad metropolitana. Toda persona discapacitada tiene derecho a que se facilite su movilidad y a la supresión de todas las barreras arquitectónicas.

11. El derecho a la conversión de la ciudad marginal en ciudad de ciudadanía, que implica el derecho de toda persona a habitar en zonas urbanas de calidad, con carácter de centralidad.

12. El derecho al gobierno metropolitano o plurimunicipal, que garantiza el derecho de toda persona, por razones de participación y de eficacia de la gestión pública, a un gobierno local de proximidad que, en las regiones más urbanizadas, puede tener una dimensión plurimunicipal o metropolitana.

La Carta de la Autonomía Municipal Iberoamericana, núcleo fundamental de la doctrina municipalista de la OICI, es un instrumento para la democracia y la participación de todos los ciudadanos. Así, en su aparta- 
do séptimo determina como fundamental la incorporación de los ciudadanos a los procesos de gobierno y a la gestión municipal, determinando que para ello deben facilitarse las vías y los cauces para una participación ciudadana efectiva ${ }^{11}$.

\section{PROXIMIDAD Y SUBSIDIARIEDAD ${ }^{12}$}

La Administración Municipal está siempre en contacto directo y personal con los ciudadanos. Esto tiene implicaciones en el tipo de funciones que dentro del sistema se le atribuyen; en las condiciones y formas de desempeñar esas funciones y en la relación de intermediación entre los ciudadanos y otros gobiernos que en muchas ocasiones le corresponde desarrollar.

- La diferenciación de funciones entre los distintos niveles de gobierno-administración responde a una distribución competencia legalmente establecida. Los ciudadanos no acostumbran a conocerlo y acuden a la Administración más cercana y asequible. Al municipio le demandan soluciones en relación con las políticas públicas que más influyen de forma directa y cotidiana en su vida. Suelen ser servicios públicos con alta variación de la necesidad individual, de carácter frecuente, directo y localizados territorialmente. Pero no sólo servicios; esto afecta también a políticas reguladoras y de defensa del orden interno. Cuando un problema social afecta a personas y colectivos específicos aparece localizado en un ámbito territorial y resulta cotidiano; los ciudadanos buscan y exigen soluciones al municipio. Son servicios y funciones muy visibles, sometidos a un control, presión y exigencia de los destinatarios. Si funcionan mal, la crítica y la desafección son inmediatas; si mejoran y responden adecuadamente a las demandas o expectativas, en reconocimiento también lo es.

- El gobierno local muestra una gran accesibilidad. En el desarrollo de las políticas públicas municipales, los ciudadanos y los grupos tiene más posibilidades de influir. Por el tamaño del «escenario»y por las relaciones que en él se dan, la política municipal es más permeable a los intereses sociales y a los requerimientos ciudadanos.

- Por su cercanía, el gobierno local actúa como agente de intermediación entre la sociedad y el sistema político en su conjunto; entre el

\footnotetext{
11 Documentos OICI, Madrid, 1999.

12 Seguimos lo planteado por Valentín MERINo EstradA, La calidad total en la Administración local. Fundamentos y orientaciones básicas, REAL, n² 291, INAP 2003.
} 
sector público y privado; entre intereses de distintos niveles y entre gobiernos que mantienen competencias en su ámbito territorial. En este contexto, el gobierno local asume una función de liderazgo, de dinamización y conducción del desarrollo social, de extraordinaria importancia.

Todo esto provoca una tendencia expansiva en las tareas y en los gastos, más allá de las competencias formales atribuidas que exige la pronta y efectiva aplicación del principio de subsidiariedad, consagrado en la Carta Europea de la Autonomía Local: «el ejercicio de las competencias públicas debe, de modo general, incumbir preferentemente a las autoridades más cercanas a los ciudadanos. La atribución de una competencia a otra autoridad debe tener en cuenta la amplitud y la naturaleza de la tarea o las necesidades de eficacia o economía» ${ }^{13}$. La subsidiariedad no es sólo cuestión de proximidad, también de capacidad, de forma que las políticas las desarrolle la Administración que asegure mayor calidad: satisfacción a costes razonables. Los municipios están mejor situados para lograrlo, pero necesitan los medios, tanto económicos como estructurales, para poder hacerlo. Por ello en España, por ejemplo, se habla desde hace tiempo del desarrollo del Pacto Local o «segunda descentralización».

Los municipios, en atención al factor proximidad, son el escenario más propicio para fortalecer la participación del ciudadano corriente en las políticas públicas y para gestionar con sistemas efectivos de calidad.

\section{Configuración en Venezuela}

\section{Desarrollo constitucional}

El Constituyente de 1999, inspirado en la más eufórica doctrina de la participación, señaló en el preámbulo de la Constitución que se aspira a una sociedad democrática y participativa. Así, redactó el artículo 6 Constitucional determinando que el Gobierno de la República es y será siempre democrático y participativo. En esta sintonía el artículo 158 Constitucional establece:

«La descentralización, como política nacional, debe profundizar la democracia, acercando el poder a la población y creando las mejores condiciones, tanto para el ejercicio de la democracia como para la prestación eficaz y eficiente de los cometidos estatales».(subrayado nuestro).

13 Cartas de Autonomía Local, UIM, Granada 1994. 
Más claro y contundente es el contenido del artículo 62, que consagra un amplio derecho de participación en los asuntos públicos a los ciudadanos y a las organizaciones de la sociedad civil, al establecer que:

\footnotetext{
«Todos los ciudadanos y ciudadanas tienen el derecho de participar libremente en los asuntos públicos, directamente o por medio de sus representantes elegidos o elegidas.

La participación del pueblo en la formación. ejecución y control de la gestión pública es el medio necesario para lograr el protagonismo que garantice su completo desarrollo, tanto individual como colectivo. Es obligación del Estado y deber de la sociedad facilitar la generación de las condiciones más favorables para su práctica».(subrayado nuestro).
}

Son varios los organismos constitucionalmente delineados como mecanismos para desarrollar la democracia participativa. Así tenemos el Consejo Federal de Gobierno (art.185), los Consejos Estadales de Planificación y Coordinación de Políticas Públicas (art.166), y en el ámbito local los Consejos Locales de Planificación Pública (art.182). Todos ellos admiten representación de la comunidad organizada.

Al regular la Constitución la configuración de la Administración Pública, artículos 141 al 143, se consagran principios que promueven el desarrollo de una gerencia pública moderna, insistiendo en que la misma está al servicio de los ciudadanos y debe orientarse por los principios de honestidad, participación, celeridad, eficacia, transparencia, rendición de cuentas, y responsabilidad.

En el ámbito local no se podía esperar menos, dada la trayectoria de la legislación municipal preexistente y sus avanzados principios en la materia $^{14}$. De especial interés es el contenido del artículo 184 Constitucional al determinar que la ley creará mecanismos abiertos y flexibles para que los Estados y los Municipios descentralicen y transfieran a las comunidades y grupos vecinales organizados los servicios que éstos gestionen previa demostración de su capacidad para prestarlos. Así, dicho artículo señala que debe promoverse:

1. La transferencia de servicios en materia de salud, educación, vivienda, deporte, cultura, programas sociales, ambiente, mantenimiento de áreas industriales, mantenimiento y conservación de áreas urbanas, prevención y protección vecinal, construcción de obras y prestación de servicios públicos. A tal efecto, podrán establecer convenios cuyos contenidos estarán orientados por los principios de interdependencia, coordinación y corresponsabilidad.

\footnotetext{
${ }^{14}$ Aparecen principios fundamentales de participación en la Ley Orgánica de Régimen Municipal, de 1989, y en el Reglamento sobre Participación de la Comunidad de 1990.
} 
2. La participación de las comunidades y ciudadanos y ciudadanas, a través de las asociaciones vecinales y organizaciones no gubernamentales, en la formulación de propuestas de inversión ante las autoridades estadales y municipales encargadas de la elaboración de los respectivos planes de inversión, así como en el ejecución, evaluación y control de obras, programas sociales y servicios públicos en su jurisdicción.

3. La participación en los procesos económicos estimulando las expresiones de la economía social, tales como cooperativas, cajas de ahorro, mutuales y otras formas asociativas.

4. La participación de los trabajadores y trabajadoras y comunidades en la gestión de las empresas públicas mediante mecanismos autogestionarios y cogestionarios.

5. La creación de organizaciones, cooperativas y empresas comunales de servicios, como fuentes generadoras de empleo y de bienestar social, proponiendo a su permanencia mediante el diseño de políticas donde aquellas tengan participación.

6. La creación de nuevos sujetos de descentralización a nivel de las parroquias, las comunidades, los barrios y las vecindades a los fines de garantizar el principio de las corresponsabilidades en la gestión pública de los gobiernos locales y estadales y desarrollar procesos autogestionarios y cogestionarios en la administración y control de los servicios públicos estadales y municipales.

7. La participación de las comunidades en actividades de acercamiento a los establecimientos penales y de vinculación de éstos con la población.

Este artículo pudiera resultar peligroso ante la rotundidad de intervención en temas de gobierno y administración efectiva, superando los límites de la participación en órganos consultivos. La experiencia nos dirá si el Constituyente acertó con esta norma. Sí diremos que la nueva realidad del Estado en Venezuela presenta un escenario donde han irrumpido las masas populares en protagonismo espectacular, ignoradas por más de cuarenta años de vigencia del sistema centralizado de partidos. Para algunos, más que en la idea o en el slogan de la participación administrativa, podría insistirse en la de transparencia administrativa, instrumentable a través de una pluralidad de formas concretas de alcance más amplio, subjetiva y objetivamente, que la propia idea de la participación ${ }^{15}$.

Lo que sí es notorio en el proceso de descentralización municipal en toda Iberoamérica, como debate de actualidad, es el espacio importante

\footnotetext{
15 Miguel SÁnchez Moron, La participación del ciudadano en la Administración Pública, Centro de Estudios Constitucionales, Madrid 1980.
} 
que tiene el tema de la participación ciudadana, como intento de aproximar la gestión municipal a los ciudadanos y promover la participación de los mismos en los asuntos que, como miembros de una comunidad, les afectan directamente ${ }^{16}$. Se trata, en definitiva, de incorporar a la comunidad en el desarrollo local, involucrando a los vecinos y haciéndoles partícipes en la toma de decisiones que les afecten ${ }^{17}$. La Constitución venezolana de 1999, la última del siglo XX y la primera del siglo XXI, está henchida de este fenómeno que recorre las sociedades de nuestra América hispana: aspira a lograr una democracia directa municipa ${ }^{18}$.

En suma, los procesos de desarrollo local deben implicar una decisiva participación de la comunidad, facilitándose por parte de las estructuras municipales los instrumentos para que sea real, o bien, cuando las circunstancias lo requieran, modificarlos para su adecuación. Es de gran importancia para los gobiernos locales que la población esté organizada a través de las más diversas expresiones (barrios, asociación de vecinos, parroquias, centros culturales u otras formas). El municipio no puede permanecer ajeno al grado de organización comunitaria, ni al desarrollo de su capacidad para promover iniciativas. Una comunidad bien organizada es más poderosa, más representativa de las inquietudes vecinales y más capaz de hacer valer con garantía esos anhelos. Es unánime entre los municipalistas la idea de que el municipio conforma, hoy por hoy, el espacio adecuado y necesario para la descentralización y la participación. Es la premisa indiscutible para el avance democrático, entendido éste no sólo como modelo político, sino también como modo de vida. La misión del municipio es la adopción de mecanismos que favorezcan la ampliación de dicha participación, especialmente cuando está en juego la formulación de políticas y la definición de prioridades de interés para los vecinos.

No debe olvidarse que, junto al énfasis puesto en la creación de un municipio participativo, existen también otros factores que se oponen a ello $^{19}$. Ya sea por causas de naturaleza estructural, asociadas a estilos y conductas político-administrativas ancladas en el pasado (clientelismo, burocratismo), ya sea por la mentalidad de la comunidad sujeta a un tra-

\footnotetext{
16 Angel Ballesteros Fernández, La participación de los ciudadanos en el gobierno local. Memorias del V Congreso Iberoamericano de Municipalistas, Tomo I, UIM-CEMCI, Granada 2000.

17 Cristina CAStro Bermejo, Descentralización Municipal y participación ciudadana en Iberoamérica, Revista Iberoamericana de Administración Pública no 2, INAP, Madrid 1999.

18 Enrique Orduña Rebollo, Democracia directa municipal, concejos y cabildos abiertos. Civitas, Madrid 1994.
}

19 FEO LA CRUZ...ob.cit. 
dicionalismo y paternalismo desfasado. Lo cierto es que no siempre pueden alcanzarse las metas de una participación eficaz y verdadera. Únicamente vencidos estos obstáculos y en plena autonomía, los municipios pueden cumplir los objetivos que lo justifican: ser una escuela de política y gobierno; ser un agente de desarrollo socio-económico y ser una entidad que presta servicios públicos.

Los gobiernos locales en mayor medida que los demás por su proximidad al ciudadano, no pueden estar ni actuar aislados ni ajenos a los ciudadanos, deben procurar ser receptivos e informar sobre sus procesos decisorios y de gestión, sin perder de vista la calidad y eficiencia en la prestación de los servicios públicos ${ }^{20}$.

Creemos propicio este contexto para recordar lo que el Tribunal Constitucional español ha dicho al respecto:

«...la participación directa que en los asuntos públicos ha de corresponder a los ciudadanos es la que se alcanza a través de las consultas previstas en la propia Constitución, procedimientos éstos en los que habrán de hacerse presentes, sin duda, los partidos y, en general, las organizaciones politicas mas no como titulares del derecho mismo a la participación, sino en lo que a los partidos políticos se refiere, como instrumentos fundamentales que son para hacerla posible, concurriendo como la Constitución quiere a la formación y manifestación de la voluntad popular».(STC 63/1987, de 20 de mayo).

El municipio delineado en la Constitución de 1999 persigue evidentemente profundizar la democracia, haciendo del gobierno local un medio franco para la participación ciudadana en los asuntos que le son propios y más vinculados.

La formación y apoyo a la comunidad para promover, fortalecer y desarrollar cabalmente su presencia en aquellos asuntos trascendentes constituye indudablemente un mecanismo de consolidación y rejuvenecimiento institucional, pues acerca al ente formal a su interlocutor natural que es la sociedad civil y con ello vigoriza su esencia, sin caer en la tentación de adaptaciones miméticas que sólo ofrecen una simple apariencia. Así no queda duda en que la opción está en el afianzamiento del municipio como instrumento de la democracia ${ }^{21}$.

Enrique Orduña ha advertido con relación a la participación en la vida local, que «... la democracia directa municipal ha sido ignorada, pos-

\footnotetext{
20 IGLESIAS MARTÍN..ob.cit.

21 Vid. Armando RodríGuEz GarcíA, Marco institucional del municipio contemporáneo, Revista de Derecho Público, nº 51, 1992.
} 
tergada e incluso perseguida, unas veces con la disculpa de alteraciones y tumultos, otras por un pretendido anacronismo o en aras de una racionalización tecnocrática y economicista más peligrosas que las anteriores $\rangle^{22}$.

\section{Desarrollo legislativo}

En Venezuela parece, al menos, que con el desarrollo de la legislación al respecto no se está ignorando ni postergando el anhelo de esa democracia directa municipal.

\section{Ley de los Consejos Locales de Planificación Pública}

Desarrollando los principios constitucionales previstos en el artículo 182 que crea el Consejo Local de Planificación Pública, aunque con cierta demora, fue decretada por la Asamblea Nacional la Ley de los Consejos Locales de Planificación Pública de 12 de junio de 2002. El Consejo Local de Planificación Pública es un órgano nacido con la finalidad de articular el principio de la participación en el gobierno local. El Constituyente animado por el cambio que implica avanzar de una democracia representativa a una democracia participativa, incorpora a la ciudadanía en la planificación pública local. Luce como una respuesta concreta en el escenario local a la ola de cambios que se están produciendo en Venezuela. Así, por mandato constitucional, la comunidad forma parte de la organización local.

Este Consejo será presidido por el Alcalde o Alcaldesa e integrado por los concejales y concejalas, los Presidentes o Presidentas de la Juntas Parroquiales y representantes de organizaciones vecinales y otras de la sociedad organizada, de conformidad con las disposiciones que establezca la ley. Estamos en presencia de un órgano colegiado, cuyo número de integrantes variará según el número de Concejales que haya en cada municipio, del número de Juntas Parroquiales, de la cantidad de organizaciones vecinales y otras de la sociedad organizada (fundaciones, asociaciones culturales, deportivas, educativas, etc)que funcionen en la localidad. La presencia de estos últimos integrantes fundamenta la importancia del Consejo al desarrollar potencialmente el principio de la participación ciudadana. Es un órgano consultivo y de carácter auxiliar.

22 Democracia directa municipal, concejos y cabildos abiertos. Civitas, Madrid 1994. 
La Constitución no establece las funciones de este especial cuerpo colegiado dejando tal tarea en manos del legislador ordinario. Pero creemos que su tarea cardinal es la de planificar en términos generales las actividades que correspondan competencialmente al municipio. La exposición de motivos de la Constitución señala que el Consejo tiene por objeto la planificación, coordinación y cooperación en la definición y ejecución de las políticas públicas. Este órgano no debe ser solamente consultivo. En una actual visión de gobernabilidad debe dársele más importancia a este concepto fundamental de planificación. Este órgano puede servir para calibrar la acción del gobierno local.

En desarrollo de su consagración constitucional la Asamblea Nacional decretó la Ley de los Consejos Locales de Planificación Pública, publicada en Gaceta Oficial en fecha 12 de junio de 2002, Número 37.463. Esta ley tiene por objeto establecer las disposiciones y bases para la organización y funcionamiento de los Consejos Locales de Planificación Pública, para hacer eficaz su intervención en la planificación que conjuntamente efectuará con el gobierno municipal respectivo, y el concurso de las comunidades organizadas. (art. 1). El Consejo Local de Planificación Pública es el órgano encargado de la planificación integral del gobierno local, para lo cual, se sujetará con lo dispuesto en el artículo 55 del Decreto $\mathrm{n}^{\circ} 1.528$ con Fuerza de Ley Orgánica de Planificación, con el propósito de lograr la integración de las comunidades organizadas y grupos vecinales mediante la participación y el protagonismo dentro de una política general de Estado, descentralización y desconcentración de competencias y recursos, de conformidad con lo establecido en la Constitución de la República Bolivariana de Venezuela. Cada Consejo Local de Planificación Pública, promoverá y orientará una tipología de municipio atendiendo a las condiciones de población, nivel de progreso económico, capacidad para generar ingresos fiscales propios, situación geográfica, elementos históricos, culturales y otros factores relevantes. En todo caso, el Consejo Local de Planificación Pública responderá a la naturaleza propia del municipio. (art. 2).

Este Consejo está integrado de la siguiente forma:

1. Un Presidente o Presidenta, quien será el Alcalde o Alcaldesa.

2. Los Concejales y Concejalas del municipio.

3. Los Presidentes o Presidentas de las Juntas Parroquiales.

4. El o los representantes de organizaciones vecinales de las parroquias, el o los representantes, por sectores, de las organizaciones de la sociedad organizada y el o los representantes de las comunidades o pueblos indígenas, donde los hubiere. Estos representantes, serán 
elegidos como lo dispone el artículo 4 de esta Ley, en un número igual a la sumatoria más uno de los integrantes mencionados en los numerales 1 al 3 de este artículo. El ejercicio de las funciones inherentes al Consejo Local de Planificación Pública será ad-honorem.(art. 3).

La ley también establece una regulación para la elección de los representantes de la comunidad organizada, sin menoscabo de las normas establecidas en la ley orgánica que regula el Poder Electoral. A ello dedica un extenso artículo 4. Así, la elección de los representantes de las organizaciones vecinales y de los sectores de la sociedad organizada, es competencia de la asamblea de ciudadanos de la comunidad o sector respectivo, para lo cual, deberá ser convocado un representante de la Defensoría del Pueblo, de su jurisdicción, quien testificará en el acta de la asamblea de ciudadanos los resultados, de dicha elección. La ordenanza respectiva determinará la forma como se realizará la organización de los sectores involucrados de las comunidades organizadas, así como el mecanismo de elección de sus representantes.

Dicha elección se harán a tres (3) niveles:

1. El representante o los representantes de las organizaciones vecinales a nivel parroquial, se elegirá o se elegirán en asambleas de las comunidades organizadas que hacen vida en el ámbito parroquial. En aquellas parroquias de gran densidad poblacional, entendida ésta en los términos que determine la Oficina Central de Estadística e Informática, se hará por elección en los términos que establezca la ley orgánica que regula la materia. La ordenanza respectiva regulará la materia.

2. Los representantes en el ámbito municipal de los distintos sectores de la sociedad civil organizada: educación, salud, cultura, deporte, producción y comercio, transporte, ecología, servicios y todos aquellos que, en general, respondan a la naturaleza propia del municipio, serán elegidos en asamblea de las comunidades organizadas del sector respectivo, mediante elección en los términos que establezca la ley orgánica que regula la materia. En aquellos municipios de gran densidad poblacional, entendida ésta en los términos que determine la Oficina Central de Estadística e Informática, se hará por elección en los términos que establezca la ley orgánica que regula la materia. La ordenanza respectiva regulará la materia. 3. El o los representantes de las comunidades o pueblos indígenas, donde los hubiere, serán elegidos de acuerdo con sus usos, costumbres y con sus organizaciones legalmente constituidas. 
El artículo 5 establece las funciones del Consejo Local de Planificación Pública, de la siguiente manera: 1. Recopilar, procesar y priorizar las propuestas de las comunidades organizadas. 2. Impulsar, coadyuvar, orientar y presentar dentro del Plan Municipal de Desarrollo las políticas de inversión del presupuesto municipal, contempladas en el artículo 178 de la Constitución de la República Bolivariana de Venezuela. Todo ello, de conformidad con los lineamientos del Plan de la Nación, los planes y políticas del Consejo Federal de Gobierno y del Consejo de Planificación y Coordinación de Políticas Públicas, con las propuestas de las comunidades organizadas.

3. Presentar propuestas y orientar el Plan Municipal de Desarrollo hacia la atención de las necesidades y capacidades de la población, del desarrollo equilibrado del territorio y del patrimonio municipal.

4. Instar y facilitar la cooperación equilibrada de los sectores públicos y privados para la instrumentación, en el municipio, de los planes suscritos.

5. Controlar y vigilar la ejecución del Plan Municipal de Desarrollo.

6. Formular y promover ante el Consejo de Planificación y Coordinación de Políticas Públicas o el Consejo Federal de Gobierno los programas de inversión para el municipio.

7. Impulsar la celebración de acuerdos de cooperación entre el municipio y los sectores privados, tendentes a orientar sus esfuerzos al logro de los objetivos del desarrollo de la entidad local.

8. Impulsar y planificar las transferencias de competencia y recursos que el municipio realice hacia la comunidad organizada, de conformidad con lo previsto en el artículo 184 de la Constitución de la República Bolivariana de Venezuela.

9. Impulsar la coordinación con otros Consejos Locales de Planificación Pública para coadyuvar en la definición, instrumentación y evaluación de planes para el desarrollo de mancomunidades, solicitando, en su caso, la intervención de los poderes nacionales y de los estados para tales efectos.

10. Atender cualquier información atinente a su competencia que solicite el gobierno nacional, estadal o municipal sobre la situación socioeconómica y sociocultural del municipio.

11. Proponer al gobierno nacional, estadal o municipal las medidas de carácter jurídico, administrativo o financiero, necesarias para el cumplimiento de las funciones y la consecución de los objetivos del municipio y del propio Consejo Local de Planificación Pública.

12. Emitir opinión razonada, a solicitud del Alcalde o Alcaldesa, sobre transferencias de competencia que el Ejecutivo Nacional, el estadal o el Consejo Legislativo Estadal, acuerden hacia el municipio. 
13. Impulsar con el poder nacional, estadal o municipal, así como con las comunidades organizadas, el Plan de Seguridad Local de Personas y Bienes.

14. Coordinar, con el Consejo de Planificación y Coordinación de Políticas Públicas y el Consejo Federal de Gobierno, los planes y proyectos que éstos elaboren en el marco de sus competencias, tomando en cuenta los planes y proyectos locales.

15. Impulsar la organización de las comunidades organizadas integrándolas al Consejo Local de Planificación Pública, de acuerdo con lo establecido en la presente Ley.

16. Interactuar, con el Consejo Municipal de Derechos, en todo lo atinente a las políticas de desarrollo del niño, del adolescente y de la familia.

17. Colaborar en la elaboración de los planes locales de desarrollo urbano y las normativas de zonificación cuyas competencias le correspondan al municipio.

18. Elaborar el estudio técnico para la fijación de los emolumentos de los altos funcionarios y funcionarias de los municipios. A tal efecto, el Consejo Local de Planificación Pública solicitará la información necesaria referida al número de habitantes, situación económica del municipio, presupuesto municipal consolidado y ejecutado, correspondiente al período fiscal inmediatamente anterior, capacidad recaudadora y disponibilidad presupuestaria municipal para cubrir el concepto de emolumentos, a los órganos que corresponda.

19. Elaborar el mapa de necesidades del municipio.

20. Elaborar un banco de datos que contenga información acerca de proyectos, recursos humanos y técnicos de la sociedad organizada.

21. Evaluar la ejecución de los planes y proyectos e instar a las redes parroquiales y comunales, a ejercer el control social sobre los mismos.

22. Las demás que le otorguen las leyes y reglamentos.

Los miembros del Consejo Local de Planificación Pública estarán obligados a cumplir con sus funciones, en beneficio de los intereses colectivos, mantendrán una vinculación permanente con las redes de los consejos parroquiales y comunales, atendiendo sus opiniones y sugerencias, y prestarán información oportunamente, de las actividades del Consejo Local de Planificación Pública. (art. 6).

Los miembros del Consejo Local de Planificación Pública tendrán un período de duración en su mandato, de acuerdo con las siguientes disposiciones: 
1. Los de elección popular, cuatro (4) años. El mandato sólo puede ser revocado a través de referendo revocatorio.

2. Los representantes a nivel municipal, de los diferentes espacios de la sociedad civil y el representante o los representantes de las organizaciones vecinales a nivel parroquial, durarán dos (2) años en sus funciones, y su mandato sólo puede ser revocado mediante una asamblea constituida bajo los mismos requisitos y formalidades establecidos para su elección, en la ley orgánica que regula la participación ciudadana y en la ordenanza respectiva que regula la materia.

3. Los representantes de las comunidades de los pueblos indígenas durarán cuatro (4) años en sus funciones. Su mandato podrá ser revocado cuando la comunidad o estos pueblos así lo estimen, de acuerdo con sus usos, costumbres y con sus organizaciones indígenas legalmente constituidas. (art. 7).

El ejercicio de las funciones inherentes al Consejo Local de Planificación Pública serán ad-honorem, excepto para los integrantes de la Sala Técnica. (art. 22).

Los artículos 8 al 11 contienen normas reguladoras de la participación de la Comunidad Organizada. Así, se establece que El Consejo Local de Planificación Pública promoverá la Red de consejos parroquiales y comunales en cada uno de los espacios de la sociedad civil que, en general, respondan a la naturaleza propia del municipio cuya función será convertirse en el centro principal de la participación y protagonismo del pueblo en la formulación, ejecución, control y evaluación de las políticas públicas, así como viabilizar ideas y propuestas para que la comunidad organizada las presente ante el Consejo Local de Planificación Pública. Una vez aprobadas sus propuestas y convertidas en proyectos, los miembros de los consejos parroquiales y comunales podrán realizar el seguimiento, control y evaluación respectivo.

Los miembros de los consejos parroquiales y comunales tendrán carácter ad-honorem.

La comunidad organizada, excepto los pueblos indígenas donde los hubiere, para postular sus representantes al Consejo Local de Planificación Pública, deberá hacerlo por intermedio de una organización civil creada de acuerdo a la ley, en asamblea de sus miembros. Los requisitos exigidos son:

1. Estar inscrita en el registro subalterno para determinar su personalidad jurídica. 
2. Presentar el libro de actas de reuniones y de asambleas.

3. Presentar constancia de la última elección, de su Junta Directiva.

4. Presentar un ejemplar de sus estatutos.

5. Presentar nómina actualizada de sus integrantes, contentiva de nombres y apellidos, cédula de identidad y dirección.

6. Inscribirse, para tal fin, en la oficina respectiva del Consejo Local de Planificación Pública.

La comunidad organizada que no reúna alguno de los requisitos indicados, pero presente actas de elección o relegitimación por asamblea, de sus miembros, o que tenga constancia de estar realizando labores en beneficio de su comunidad, por lo menos durante un año consecutivo, será inscrita en la oficina de control del Consejo Local de Planificación Pública y se le orientará y apoyará para que adquiera personalidad jurídica.

La Representación de la comunidad organizada, a través de las organizaciones vecinales y otras de las comunidades estará vinculada al plan rector municipal, siempre que formalmente pertenezcan a sectores de los enunciados en el numeral 1 del artículo 4 de la Ley, antes indicado. Los integrantes de dichos sectores, constituidos en asamblea, elegirán sus correspondientes representantes o voceros ante el Consejo Local de Planificación Pública, de conformidad con la ordenanza que establezca la reglamentación del Consejo Local de Planificación Pública, aprobarán y priorizarán sus necesidades que se podrán transformar, previa consideración de viabilidad de las mismas, en planes y proyectos de obras o servicios. (art.10).

El artículo 11 establece que todo proyecto presentado al Consejo Local de Planificación Pública deberá ser aprobado previamente por la comunidad respectiva, reunida en asamblea, a fin de garantizar el cumplimiento del artículo 62 de la Constitución de la República Bolivariana de Venezuela, que consagra el principio de la participación y el protagonismo. El orden de prioridad de los proyectos lo determinará la comunidad constituida en asamblea de acuerdo con sus necesidades, salvo los casos de emergencia debidamente comprobada.

Los artículos 12 al 15 contienen lo relacionado con el presupuesto consolidado de inversión. Dicho presupuesto de inversión municipal se elaborará de acuerdo con las necesidades prioritarias presentadas por las comunidades organizadas, en concordancia con lo estimado por la Alcaldía, en el presupuesto destinado al referido sector. También con los proyectos generales sobre urbanismo, infraestructura, servicios y vialidad que demande el municipio. 
Existe la obligación de información presupuestaria. En efecto, a fin de orientar el Presupuesto de Inversión Municipal, el Alcalde o la Alcaldesa presentará al Consejo Local de Planificación Pública y a las comunidades organizadas, en reunión extraordinaria que deberá efectuarse con quince (15) días continuos de antelación a la reunión formal del Consejo Local de Planificación Pública, la cifra o monto total de inversión de cada sector, determinado en el artículo 8 de la Ley, incluyendo los detalles a que haya lugar.

También las alcaldías están en la obligación de darle curso a los proyectos que las comunidades organizadas presenten, con cargo a los porcentajes de las asignaciones que correspondan a éstas, por concepto de leyes que otorguen y transfieran recursos para las comunidades organizadas.

El Presupuesto de Inversión Municipal estará dirigido al desarrollo humano, social, cultural y económico del municipio, tomando en cuenta las variables de población y pobreza de cada comunidad, debiendo cubrir con:

1. Los proyectos prioritarios, que presenten las comunidades organizadas.

2. Los proyectos generales sobre urbanismo, infraestructura, servicios y vialidad.

3. El fondo de emergencia, para atender desastres naturales, calamidad pública e imprevistos. Este fondo, será administrado por el Alcalde o Alcaldesa, previa aprobación del Concejo Municipal, con participación del Consejo Local de Planificación Pública que hará el seguimiento respectivo, para que los recursos sean invertidos en los fines a los que se refiere esta norma. La ordenanza respectiva que regula la materia determinará el porcentaje que le corresponda al fondo de emergencia.

Los artículos 16 al 18 se refieren al funcionamiento del Consejo Local de Planificación Pública. Así, los Consejos Locales de Planificación Pública deberán reunirse ordinariamente por lo menos una vez, trimestralmente, sin menoscabo de las reuniones extraordinarias que ameriten realizar, de acuerdo con las necesidades del municipio.

Dicho Consejo será convocado por el Alcalde o Alcaldesa o por solicitud del treinta por ciento (30\%) de los miembros que lo conforman. En ausencia del Alcalde o Alcaldesa, éste será presidido por la máxima autoridad presente en la reunión. 
Las decisiones del Consejo Local de Planificación Pública se tomarán por mayoría absoluta de sus miembros.

El Plan de Inversión Municipal, aprobado mediante este mecanismo, será remitido a la Cámara Municipal para su aprobación definitiva.

La Cámara Municipal, de acuerdo con su competencia, podrá reformar el Plan de Inversión Municipal previa consulta con los sectores o espacios de la vida civil y las organizaciones de la comunidad, inscritas en el Consejo Local de Planificación Pública y, mediante una exposición razonada sobre los supuestos de hecho y de derecho que motiva la reforma. De no cumplirse estos extremos de ley, el plan original se considerará aprobado.

El artículo 19 crea una Sala Técnica dependiente de la Alcaldía que cumplirá con las siguientes funciones:

1. Proveer la información integral automatizada, en la medida de lo posible, con el propósito de asegurar la información sectorial codificada, necesaria para la planificación, el control de gestión y la participación de la comunidad organizada.

2. Crear y poner en funcionamiento la Unidad de Planes y Proyectos, integrada por profesionales especializados en la materia de planificación.

3. Garantizar la información sobre el registro y control de las asociaciones de las comunidades organizadas participantes ante el Consejo Local de Planificación Pública.

Todos los habitantes del municipio tendrán derecho a acceder a la información de la Sala Técnica, de conformidad con lo establecido en el artículo 51 de la Constitución de la República Bolivariana de Venezuela.

La elección de los miembros de la Sala Técnica será por concurso público, atendiendo a las especificidades, necesidades y naturaleza del municipio, de conformidad con la ordenanza respectiva que regula la materia. (art. 20).

Los artículos 21 al 24 contienen previsiones presupuestarias. Así se establece que la Alcaldía tomará las previsiones pertinentes que garanticen el cumplimiento de las funciones propias del Consejo Local de Planificación Pública. A tal efecto, en el presupuesto de ingresos y gastos de la Alcaldía, éstas deberán estar debidamente identificadas. Una vez elaborado el Presupuesto de Inversión Municipal a que se refiere esta Ley, será enviado por el Alcalde o Alcaldesa, a la Dirección de Presupuesto y a la Cámara Municipal, para ser sometido a su consideración y aprobación, en un lapso no mayor de sesenta (60) días. 
Sin menoscabo de las facultades contraloras y fiscalizadoras que le corresponden a la Contraloría Municipal y a la Contraloría General de la República, las comunidades organizadas podrán vigilar, controlar y evaluar la ejecución del Presupuesto de Inversión Municipal, en los términos que establezca la ley nacional que regule la materia. (art. 24).

La ley establece una sanción para el Alcalde o Alcaldesa, o el funcionario accidental que, en los primeros ciento veinte (120) días de la vigencia de esta Ley dejare de poner en funcionamiento el Consejo Local de Planificación Pública, en su respectiva Alcaldía, previa aprobación de la partida de funcionamiento. La sanción impuesta por la Contraloría Municipal será de multa de mil unidades tributarias (1000 U.T.) a dos mil unidades tributarias (2000 U.T.). El monto de la multa ingresará al fisco del respectivo municipio.(art. 25).

La ley establece que el Consejo Local de Planificación Pública elaborará y dictará su propio Reglamento Interno dentro de los sesenta días siguientes a su instalación. De igual forma se ordena a las Cámaras Municipales elaborar y aprobar la ordenanza respectiva del Consejo Local de Planificación Pública dentro de los treinta (30) días hábiles siguientes, contados a partir de la entrada en vigencia de la Ley.

Los consejos parroquiales y comunales son considerados en la Ley Orgánica del Poder Público Municipal como instancias del Consejo Local de Planificación Pública. (art. 112).

Para la más autorizada doctrina nacional se produce un encasillamiento asambleístico de la participación ciudadana en este órgano público ${ }^{23}$.

\section{Ley Orgánica del Poder Público Municipal}

Así las cosas, aparece en el escenario normativo la Ley Orgánica del Poder Público Municipal de 08 de junio de 2005, y consagra todo el título VI a la participación protagónica de los ciudadanos en la gestión local. De por sí el título es sugestivo, aunque sea más formal que real, esperando que no se convierta en un brindis al sol.

La Ley establece unos principios generales de la actuación municipal sobre la participación siguiendo de cerca los consagrados en la Constitu-

\footnotetext{
23 Véase Allan R. BREWER-CARÍAs, Introducción general al régimen del Poder Público Municipal, en la obra Ley Orgánica del Poder Público Municipal Estudios, EJV, Caracas 2005.
} 
ción, y también establece los mecanismos concretos para el ejercicio de dicha participación ${ }^{24}$.

\section{Principios generales}

1. Referencia al Municipio como unidad política primaria «...para el efectivo ejercicio de la participación protagónica del pueblo en los asuntos propios de la vida local» (art. 1); la promoción de la participación (art. 4.9); incluir la participación en su gestión pública (art. 2); como espacio primario para la participación (art. 7).

2. La parroquia como demarcación local que debe promover la participación (art. 30, 37).

3. Referencia a la normativa de las Mancomunidades que deben contener los mecanismos de participación (art. 43).

4. La participación en los municipios indígenas (art. 50, 279).

5. Los municipios y demás entidades locales deberán favorecer la constitución y desarrollo de las diversas formas de organización de la sociedad, destinadas a la defensa de los intereses colectivos. También deberán facilitar a dichas organizaciones, la información sobre la gestión pública local y dentro de sus posibilidades, el uso de los medios públicos y el beneficio de subsidios o aportes para la realización de sus fines; además promover, facilitar y proveer la formación ciudadana a través de programas diseñados a tal fin. (Artículo 260).

6. La participación protagónica del pueblo en la formación, ejecución y control de la gestión pública municipal es el medio necesario para garantizar su completo desarrollo tanto individual como colectivo, dentro del Municipio. Las autoridades municipales deberán promover y garantizar la participación de los ciudadanos y ciudadanas en la gestión pública y facilitar las formas, medios y procedimientos para que los derechos de participación se materialicen de manera efectiva, suficiente y oportuna. (Artículo 253).

6. Los ciudadanos y ciudadanas tienen derecho a obtener información general y específica sobre las políticas, planes, decisiones, actuaciones, presupuesto, proyectos y cualesquiera otras del ámbito de la actividad pública municipal. Asimismo, podrán acceder a archivos y registros administrativos, en los términos de la legislación nacional aplicable. Igualmente, tienen derecho a formular

24 Idem. 
peticiones y propuestas; y a recibir oportuna y adecuada respuesta; a la asistencia y apoyo de las autoridades municipales en sus actividades para la capacitación, formación y educación a los fines del desarrollo y consolidación de la cultura de participación democrática y protagónica en los asuntos públicos, sin más limitaciones que las dictadas por el interés público y la salvaguarda del patrimonio público. (Artículo 254).

7. Los ciudadanos y ciudadanas de la parroquia tienen el derecho y el deber de participar(Artículo 278).

8. El Concejo Municipal requerirá, de conformidad con lo que dispongan los reglamentos, la cooperación vecinal para labores de asesoramiento (Artículo 270).

9. La obligación de los Municipios de promover la participación ciudadana (arts.56, 70,71, 256, 270).

10. Obligación de los Organos del Poder Público Local de incorporar la participación en la gestión pública (arts. 75, 88, 95).

11. Que la administración local involucre a los ciudadanos en su función (art.76).

\section{Expresiones}

Para efectos de la Ley, los derechos de participación en la gestión local se ejercen mediante actuaciones de los ciudadanos y ciudadanas, y de la sociedad organizada, a través de sus distintas expresiones, entre otras:

1. Obteniendo información del programa de gobierno del alcalde o alcaldesa, del Plan Municipal de Desarrollo, de los mecanismos para la elaboración y discusión de las ordenanzas, y, en especial, de la formulación y ejecución del presupuesto local; de la aprobación y ejecución de obras y servicios, de los contenidos del informe de gestión y de la rendición de cuentas, en términos comprensibles a los ciudadanos y ciudadanas.

2. Presentando y discutiendo propuestas comunitarias prioritarias en la elaboración del presupuesto de inversión de obras y servicios, a cuyo efecto el gobierno municipal establecerá mecanismos suficientes y oportunos.

3. Participando en la toma de decisiones, a cuyo efecto las autoridades municipales generarán mecanismos de negociación, espacios de información suficiente y necesaria e instancias de evaluación. (Art. 255).. 


\section{Medios de Participación}

Los medios de participación del pueblo en ejercicio de su soberanía, son aquellos a través de los cuales los ciudadanos y ciudadanas podrán, en forma individual o colectiva, manifestar su aprobación, rechazo, observaciones, propuestas, iniciativas, quejas, denuncias y, en general, para expresar su voluntad respecto a asuntos de interés colectivo.

Los ciudadanos y ciudadanas, y sus organizaciones, tienen el derecho y el deber de utilizar los medios de participación señalados en la Ley. Los municipios deberán legislar acerca de los requisitos exigibles para demostrar el interés legítimo local de aquellos interesados en el ejercicio de alguno de estos medios de participación, sin menoscabo de los derechos y limitaciones que establece la Constitución de la República Bolivariana de Venezuela y la legislación aplicable.(Artículo 262).

Los medios de participación serán desarrollados de acuerdo a la realidad y condiciones de cada Municipio, mediante los instrumentos jurídicos correspondientes para señalar los requisitos, procedimientos, períodos, condiciones y demás elementos que se requieran para hacer efectivo su cumplimiento en el Municipio, de conformidad con lo establecido en la Constitución de la República Bolivariana de Venezuela, en la LOPPM y otras normas. (Artículo 257).

Los medios de participación son, entre otros, los siguientes (art. 260 al 277): Cabildos abiertos, asambleas ciudadanas, consultas públicas, iniciativa popular, presupuesto participativo, control social, referendos, iniciativa legislativa, medios de comunicación social alternativos, instancias de atención ciudadana, autogestión, y cogestión. El enunciado de estos medios específicos no excluye el reconocimiento y desarrollo de otras formas de participación en la vida política, económica, social y cultural del Municipio. (Artículo 261).

\section{Cabildos abiertos}

La iniciativa para convocar a cabildos abiertos corresponde al Concejo Municipal, a las Juntas Parroquiales por acuerdo de la mayoría de sus integrantes; al alcalde o alcaldesa y a los ciudadanos y ciudadanas, de conformidad con lo establecido en la respectiva ordenanza. (Artículo 263). Las decisiones adoptadas en cabildos abiertos serán válidas con la aprobación de la mayoría de los presentes, siempre y cuando sean sobre 
asuntos atinentes a su ámbito espacial y sin perjuicio de lo establecido en la legislación respectiva.(Artículo 264).

\section{Asambleas ciudadanas}

La Asamblea de ciudadanos y ciudadanas es un medio de participación en el ámbito local de carácter deliberativo, en la que todos los ciudadanos y ciudadanas tienen derecho a participar por sí mismos, y cuyas decisiones serán de carácter vinculante. (Artículo 265) Estará referida a las materias que establece la ley correspondiente, debe ser convocada de manera expresa, anticipada y pública. Sus decisiones tienen carácter vinculante para las autoridades, y han de contribuir a fortalecer la gobernabilidad, impulsar la planificación, la descentralización de servicios y recursos, pero nunca pueden ser contrarias a la legislación y los fines e intereses de la comunidad y del estado. (Artículo 266).

Todo lo referido a iniciativa, procedimiento, ámbito, materia, validez, efectos vinculantes y, comisión de control y seguimiento, será desarrollado por la ley especial que trata la materia. Esto pudiera dificultar en la práctica el funcionamiento de dicha figura.

\section{Consultas públicas}

El Consejo Municipal deberá consultar a los ciudadanos y ciudadanas y a la sociedad organizada, durante el proceso de discusión y aprobación de los proyectos de ordenanzas, a los fines de promover la incorporación de sus propuestas. Esta consulta se hará a través de diversas modalidades de participación, que garanticen una consulta abierta a los efectos de aprobar su contenido, todo de acuerdo con lo establecido en su Reglamento Interior y de Debates, y demás normativas relativas a la materia de participación.

El incumplimiento de este requisito será causal para la nulidad del respectivo instrumento jurídico.(Artículo 268).

Los actos de efectos generales que afecten el desarrollo y la conservación ambiental del Municipio o de la parroquia, deberán ser consultados previamente por las autoridades municipales entre las organizaciones vecinales y otras de la sociedad organizada. En caso contrario, estarán viciados de nulidad absoluta. (Artículo 269). 


\section{Iniciativa popular}

El Concejo Municipal deberá abrir espacios de discusión e intercambios de opiniones a los ciudadanos y ciudadanas para considerar materias de interés local. Estas materias serán inscritas en el orden del día y en dicha sesión, el público asistente podrá formular preguntas, emitir opiniones y hacer proposiciones. El Concejo Municipal deberá dar a los vecinos respuesta oportuna y razones a sus planteamientos y solicitudes. En todo caso, para la celebración de esta reunión, se convocará, entre otras, a organizaciones vecinales, gremiales, sociales, culturales, educativas y deportivas de la comunidad. En la ordenanza correspondiente se regulará, según la especificidad y diversidad municipal, las formas y procedimientos para hacer efectivo el ejercicio de este deber legal. (Artículo 267)

\section{Presupuesto participativo}

El presupuesto participativo es el resultado de la utilización de los procesos mediante los cuales los ciudadanos y ciudadanas del Municipio proponen, deliberan y deciden en la formulación, ejecución, control y evaluación del presupuesto de inversión anual municipal. Todo ello con el propósito de materializarlo en proyectos que permitan el desarrollo del Municipio, atendiendo a las necesidades y propuestas de las comunidades y sus organizaciones en el Concejo Local de Planificación Pública. (Artículo 271)

\section{Control social}

El control social es un mecanismo a través del cual todo ciudadano y ciudadana, individual o colectivamente participa en la vigilancia y control de la gestión pública municipal, en la ejecución de programas, planes y proyectos, en la prestación de los servicios públicos municipales, así como en la conducta de los funcionarios públicos, para prevenir, racionalizar y promover correctivos. (Artículo 272). Los ciudadanos y ciudadanas y sus organizaciones ejercerán el control social sobre la gestión municipal. A estos fines, las autoridades municipales deberán dar la mayor publicidad a los de gestión de interés general, tales como proyectos, licitaciones, contrataciones, costos de las mismas y elementos relevantes. Para ejercer este control social, los ciudadanos y ciudadanas y sus organizaciones podrán solicitar la información y documentación administrativa que sean de interés para la comunidad; la administración municipal está 
en la obligación de suministrarlas. (Artículo 275). Al respecto el articulo 259 de la Ley ya prevee que los ciudadanos tienen derecho a organizarse en contralorías sociales.

Los ciudadanos y ciudadanas podrán solicitar que, a través de alguno de los medio de participación previstos en el Municipio, al alcalde o alcaldesa, los concejales o concejalas y el cuerpo colegiado de las juntas parroquiales rindan cuenta de una gestión determinada, antes de la finalización de su mandato. (Artículo 274)

\section{Referendos}

La solicitud y validez del referendo consultivo, revocatorio, abrogatorio o aprobatorio, deberá cumplir con los requisitos establecidos en la Constitución de la República Bolivariana de Venezuela y en la legislación electoral; y deberá hacerse ante el Consejo Nacional Electoral quien organizará, administrará, dirigirá y vigilará todos los actos relativos a los referendos. La convocatoria a referendos sobre un proyecto de ordenanza o cualquier materia objeto de consulta, solo podrá hacerse una sola vez, en el mismo período constitucional. (Artículo 276)

\section{Iniciativa legislativa}

Los ciudadanos y ciudadanas, en un porcentaje no menor al cero coma uno por ciento $(0,1 \%)$ de los electores del Municipio, podrán presentar proyectos de ordenanzas o de modificación de las ya vigentes. Estos proyectos de ordenanzas deberán ser sometidos a la consideración del Concejo Municipal para su admisión o rechazo; previamente, el Concejo Municipal deberá fijar una reunión con los presentadores de la iniciativa legislativa a fin de discutir su contenido. Una vez examinado el proyecto, el Congreso Municipal deberá pronunciarse sobre su admisión o rechazo dentro de los treinta días siguientes a su presentación.

Admitido el proyecto, el debate del mismo deberá iniciarse en un lapso de treinta días siguientes. Si el debate no se inicia dentro del lapso antes señalado, el proyecto se someterá a consulta popular de conformidad con lo establecido en la legislación electoral. El Concejo Municipal deberá motivar el rechazo a la iniciativa cuando sea el caso. (Artículo 277). 


\section{Organizaciones parara la participación}

Los ciudadanos y ciudadanas podrán organizarse con el objeto de coadyuvar en el ejercicio del control, vigilancia, supervisión y evaluación de la gestión pública municipal. (Artículo 273) Dichas organizaciones ejercerán sus actividades sobre cualquier nivel o sector de la administración municipal y sobre particulares que cumplan funciones públicas. Estas organizaciones deben estar inscritas en un registro sistematizado que, a tal efecto, llevará cada Municipio.

Sin perjuicio de lo dispuesto en la legislación nacional que regula la participación ciudadana, las organizaciones tendrán, entre otros, los siguientes deberes y obligaciones:

1. Comunicar a la ciudadanía los avances y resultados de los procesos de control, vigilancia, supervisión y evaluación realizados.

2. Presentar informe sobre los avances y resultados de sus actividades a los órganos y entidades que ejecutan el programa, proyecto o contrato, realizando las recomendaciones que estimen pertinentes.

3. Remitir el informe de avances y resultados de sus actividades a los órganos de control fiscal y demás organismos públicos competentes.

4. Denunciar ante las autoridades competentes los actos, hechos u omisiones presuntamente irregulares que hubieren detectado.

En este aspecto observamos que el legislador no señala cuáles son esas organizaciones para la participación, y no hace referencia ninguna a las Asociaciones de Vecinos que tanta importancia tenían en la legislación derogada. A pesar de ello pensamos que pueden ser, conforme a esta norma, una forma válida y legítima para ejercer la participación ciudadana en la vida local.

\section{Descentralización de Servicios a las Comunidades y Grupos Vecinales Organizados}

Los municipios de acuerdo a su ordenanza y a las leyes que regulan la materia, descentralizarán y transferirán a las comunidades y grupos vecinales organizados la prestación de los servicios públicos municipales, previa demostración de su capacidad para prestarlos. (Artículo 280).

Los ciudadanos y ciudadanas tienen derecho a requerir y utilizar los servicios públicos locales y a participar en la formación de los planes y 
proyectos para su dotación, ejecución, gestión y evaluación. Igualmente, de forma organizada, tienen derecho a la gestión de los servicios públicos conforme a la legislación vigente respectiva. Asimismo, están obligados a contribuir al mantenimiento, preservación y mejora de la calidad de los mismos. (Artículo 258).

Las comunidades y grupos vecinales organizados que soliciten la descentralización o transferencia de un servicio público municipal deberán demostrar como mínimo(Artículo 281):

1. Capacidad legal.

2. Formación profesional o técnica en el área relacionada con el servicio.

3. Experiencia previa en gestión de servicios públicos o en áreas afines del servicio solicitado.

4. Comprobación por certificación emitida por el Municipio, de los planes de formación ciudadana.

5. Comprobación por certificación emitida, de curso en el área.

6. Legitimidad ante la comunidad involucrada.

7. Presentación del proyecto.

8. Cualquier otro que se determine en las leyes, reglamentos y ordenanzas.

La descentralización y la transferencia de servicios y recursos se harán mediante convenios, suscritos entre el Municipio y la comunidad o grupo vecinal organizado legalmente constituido, previa elaboración del programa del servicio solicitado, de acuerdo a lo establecido en las normativas que regulan la materia. (Artículo 282). El Municipio podrá intervenir el servicio o reasumir la prestación del servicio público transferido o descentralizado a comunidades y grupos vecinales organizados, cuando se deje de prestar el servicio o se preste deficientemente.

Para que proceda esta medida será necesario el voto favorable de la mayoría absoluta de los integrantes del Concejo Municipal. (Artículo 283)

El Artículo 284 de la Ley deja en manos del los Consejos Legislativos de los Estados, establecer el procedimiento de transferencia y la forma de supervisión de los servicios públicos a ser descentralizados y transferidos a los municipios, a las comunidades y a los grupos vecinales organizados. 